\title{
Grasslands Tribute: a multi-purpose white clover for Australasia
}

\author{
D.R. WOODFIELD ${ }^{1}$, P.T.P. CLIFFORD ${ }^{1}$, I.J. BAIRD ${ }^{1}$, G.R. COUSINS ${ }^{1}$, J.E. MILLER ${ }^{1}$, \\ K.H. WIDDUP ${ }^{1}$ and J.R. CARADUS ${ }^{2}$ \\ ${ }^{1}$ AgResearch, Grasslands Research Centre, PB 11008, Palmerston North \\ ${ }^{2}$ Dexcel Ltd, $P B$ 3221, Hamilton \\ derek.woodfield@agresearch.co.nz
}

\begin{abstract}
Grasslands Tribute is a medium-large leaved white clover released in 2003. It was initially bred for drought tolerance and winter activity in Victoria, Australia from crosses among elite New Zealand germplasm. Tribute was then screened for agronomic performance in New Zealand and reselected for medium-large leaf size, uniform flowering pattern, absence of foliar disease and high seed yield potential. Almost half of the 11 parental lines of Tribute came from half-sib families based on a Syrian accession with the remaining half-sibs based on Sustain, Southern Europe II and Crau in approximately equal proportions. The decision to release Tribute was based on its consistent performance and persistence under grazing in a series of seven New Zealand trials. Tribute was the best medium-large leaved variety under both sheep and dairy grazing, with only the large-leaved Kopu II having better performance under dairying. It shows strong growth in all seasons but has very good coolseason growth, and good drought tolerance in Canterbury.
\end{abstract}

Keywords: breeding, cultivars, dairy, sheep, Trifolium repens, white clover

\section{Introduction}

Soil moisture deficits reduce white clover (Trifolium repens L.) productivity, nitrogen fixation and persistence, and result in lower animal performance in many regions of Australia and New Zealand (Williams et al. 1990; Ayres et al. 1996). White clover has a shallow root system and is particularly vulnerable to drought during spring when individual plant size is at its smallest (Brock 1988), while the more common summer and autumn droughts can result in collapse of stolon populations due to a combination of high soil surface temperatures and soil moisture deficits (Archer \& Robinson 1989). Uneven distribution of seasonal rainfall, slope, aspect and low soil water holding capacity can all contribute to soil moisture deficits. Improving the drought tolerance and persistence of white clover cultivars available to Australasian farmers has been a long-term breeding objective (Woodfield \& Caradus 1987; van den Bosch et al. 1993; Ayres et al. 1996). A collaborative programme was initiated in 1991 between AgResearch and Darratech, Victoria to provide better selection pressure for drought stress. Exposure to prolonged drought stress frequently experienced in Victoria was used to identify white clover lines and genotypes with better persistence and productivity. This paper outlines the breeding history, morphology and agronomic performance of Grasslands Tribute, the first cultivar to be released from this programme.

\section{Origin and breeding}

Grasslands Tribute, formerly known as GC75, was developed from an original collection of 20 white clover lines that included several Australian ecotypes, a range of New Zealand cultivars and breeding lines, and three ecotypes collected from Southern Europe and Syria. The ecotypes from Southern Europe were collected in 1988 (Caradus et al. 1990), while the Syrian line had exhibited drought tolerance, rust resistance and high DM yield (Caradus et al. 1991; Barker et al. 1993). This gene pool was screened at Hamilton, Victoria, from 1989 to 1992, and 45 genotypes were selected in 1992 from four lines (Crau, Southern Europe II, Syrian and Sustain) on the basis of their persistence and overall herbage yield. These genotypes were polycrossed at Hamilton, Victoria, in summer 1992/1993 and the resulting 45 half-sib families were sown at Hamilton in autumn 1993 with four control cultivars Kopu, Tamar, Irrigation and Tahora. Based on performance after 2 years, 25 half-sib families were selected for improved autumn/winter growth and drought tolerance. These 25 half-sib families were subsequently screened and reselected for mediumlarge leaf size, uniformity of flowering pattern, absence of foliar disease and high seed yield potential at Lincoln, New Zealand in 1995/1996. Elite plants from eleven half-sib families originating from Sustain (2 half-sib families), Crau (2), Syrian (5) and Southern Europe II (2) were recombined to produce the pre-nucleus generation in 1996/1997. Plant Variety Rights were granted for Grasslands Tribute in March 2002 (MAF 2002). 


\section{Materials and methods}

Morphological measurements: Detailed morphological data were collected in space-planted Plant Variety Rights trials at Palmerston North in 2000/2001 and 2001/2002. These measurements were made on at least 50 genotypes per cultivar and included cyanogenesis $(\%)$, leaf size $\left(\mathrm{cm}^{2}\right)$, growth habit ( $1=$ prostrate to $9=$ erect), petiole length $(\mathrm{mm})$, stolon internode length $(\mathrm{mm})$, stolon diameter $(\mathrm{mm})$, peduncle length $(\mathrm{mm})$, the number of florets per inflorescence, and days from first flower to $50 \%$ flowering.

Ag ronomic performance: Tribute has been evaluated in seven trials (four in the North Island and three in the South Island), with each trial running for at least 2 years and in most cases for 3 years. Six of these trials have been managed using rotational grazing by sheep while the seventh trial was managed using rotational grazing by dairy cows.

Individual plots in all trials contained 10 plants in a 1-m long row with 1-m intervals between plots in each direction. Each trial contained between 19 and 90 white clover lines with at least four replicates and most commonly six replicates of each line. The performance of 12 cultivars that were present in all North Island sheep- and dairy grazed trials (12 cultivars) are reported here. The white clover cultivar Apex referred to in this paper is also known as Crusader (Woodfield et al. 2001). It is marketed as Apex in New Zealand and as Crusader in Australia and Europe to avoid confusion with Crusader ryegrass. Only three cultivars (Huia, Demand and Tribute) were present in all three South Island trials; therefore we have summarized the results from these trials into one 3 -year trial with seven cultivars and two 2-year trials with five cultivars.

Clover performance was assessed visually on a scale of $1=$ low yield to $10=$ high yield prior to each grazing. Seasonal DM harvests were also collected but as the ranking of cultivars was similar from visual and DM cuts in all trials we have presented the more extensive visual data. Stolon density was measured annually on all trials, with the exception of the 3year sheep grazed trial in Canterbury for which only a visual assessment of stolon density is available.

Data were analysed from each trial separately, and then reanalysed for the combined North Island and South Island trial data sets. To allow comparison among cultivars and trials, data were summarised by year and season and are presented relative to Grasslands Huia.

Data on clover root weevil tolerance is adapted from Eerens et al. (2001) and includes 20 white clover cultivars that were bred in New Zealand or were bred overseas but are commercially available in New Zealand.

\section{Results and discussion \\ Morphological measurements}

Tribute is a medium to medium-large-leaved cultivar with a high frequency of cyanogenic plants (Table 1) and good stolon growing point density (Table 3 ). Larger leaf size and upright growth habit are associated with increased yield potential of white clover, however, stolon growing point density, which is an important factor in improved persistence, can be negatively correlated with leaf size (Caradus et al. 1997). Tribute has larger leaf area than Apex, Huia and Demand but is smaller than Sustain and Challenge. Tribute had the highest frequency of cyanogenic genotypes $(95 \%)$ among the white clover cultivars evaluated in the PVR trials (Table 1). Improved persistence and productivity in New Zealand are strongly associated with a higher frequency of cyanogenic plants (Caradus \& Williams 1989; Crush \& Caradus 1995). Tribute has comparable growth habit and stolon diameter to other mediumto medium-large leaved cultivars such as Apex, $\mathrm{NuSiral}$ and Sustain. Tribute is an early-season variety, flowering about 10 days earlier than main-season varieties such as Huia, Demand, Kopu and Kopu II. The peduncle length of Tribute is similar to Apex, Huia, NuSiral and Demand but only Kopu and Kopu II have significantly more florets per inflorescence (Table 1).

\section{Agronomic performance}

Tribute has performed well in a series of seven trials, conducted in Canterbury and Manawatu (Tables 25). In the Manawatu dairy trial, the larger-leaved cultivars (Kopu II, Kopu, Pitau and Sustain) and two medium-leaved varieties (Tribute and Apex) performed best (Table 2). Tribute performed well in all years and its overall performance was second only to Kopu II, a cultivar developed specifically for dairy grazed farm systems (Table 2; Woodfield et al. 2001). Tribute had lower perfomance than Apex in the establishment year but was better than Apex in third year performance, which indicates good persistence. Kopu II, Apex, Tribute and Pitau performed best in the second year when white clover plants shift from depending on the seedling taproot to depending on nodal roots (Table 2).

In the three sheep-grazed trials in the North Island, Tribute and Apex had the best overall performance (Table 2). Tribute and Apex had significantly better establishment year performance than the other 


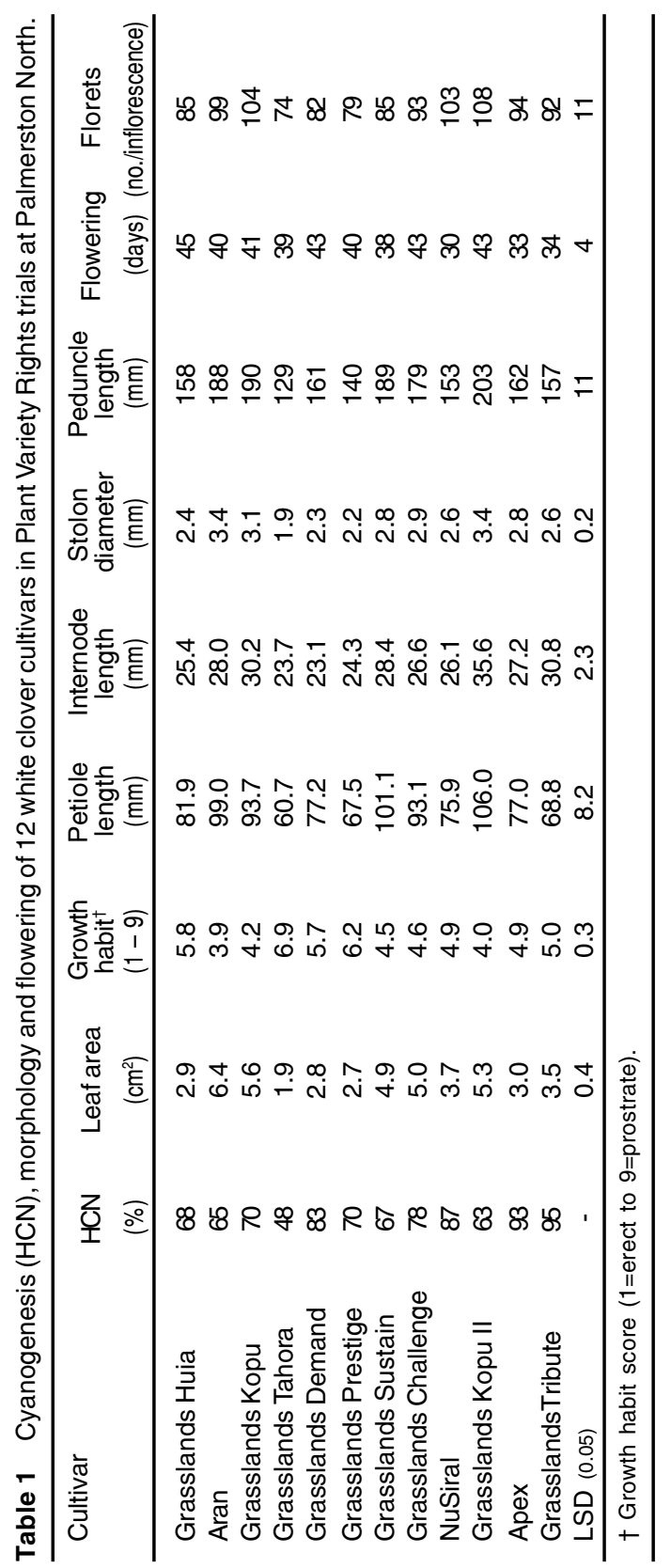

cultivars, while Demand and Prestige had comparable second year performance to these two varieties. The persistence of the smaller-leaved cultivars (Demand, Tahora and Apex), based on year 3 performance, was slightly better than Tribute, Sustain, Challenge and Kopu II (Table 2).

Three cultivars, Tribute, Apex and Kopu II, exhibited superior cool-season growth in the North Island (Table 3). Good winter activity was expected for Tribute because winter activity is very important

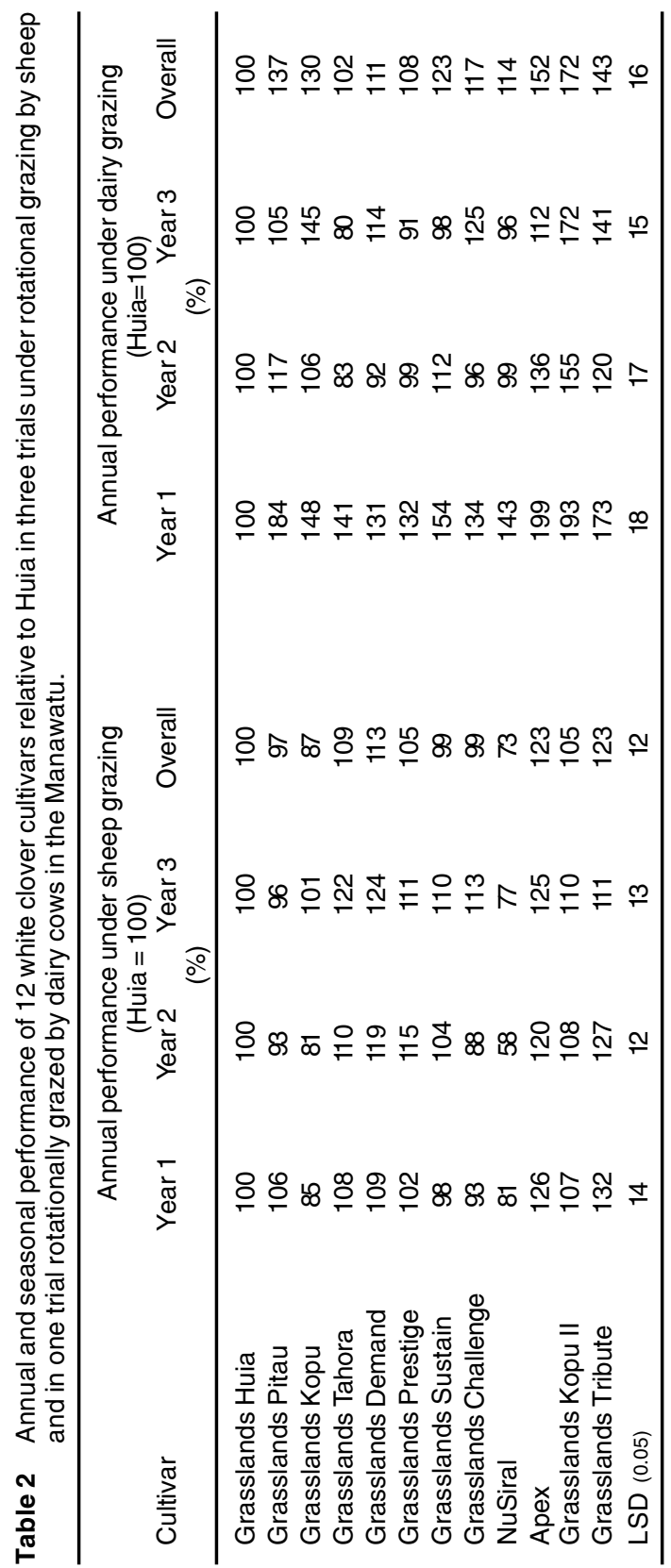

in Victoria where the initial screening was done. Tribute also had strong warm-season growth, with its summer and autumn performance being top equal with Apex and superior to all other cultivars except Demand and Kopu II in summer and autumn (Table 3 ). These differences in seasonal growth were also reflected in the South Island sheep-grazed trial with Tribute and Apex showing better winter growth than the other cultivars. Huia, Prop and Kopu II had significantly worse spring growth than the top three 
cultivars (Demand, Prestige and Tribute) (Table 4). The summer and autumn performance of Tribute in the South Island was also amongst the top group of cultivars that included Demand and Prestige.

In the three sheep-grazed South Island trials,
Tribute had strong performance and persistence (Tables 4 and 5). The overall performance of Tribute was equivalent to Demand, Prestige and Apex, but the third year performance of Tribute was significantly better than all other cultivars (Table 4). The newer cultivars (Tribute, Apex, Colt, Demand, Prestige and Kopu II) all had better persistence than Huia and Prop under rotational grazing (Table 4). Similarly in the two-year trials, Tribute had significantly better yield than Demand and Huia (Table 5).

\section{Persistence}

High stolon density is an important characteristic for production and persistence in intensively grazed pastures. The stolon growing point density of Tribute is slightly higher than Huia based on both visual assessment and in situ counts (Tables 3, 4 and 5). In the North Island trials only Prestige had significantly higher

Table 4 Annual and seasonal performance of seven white clover cultivars relative to Huia under rotational sheep grazing in Canterbury.

\begin{tabular}{|c|c|c|c|c|c|c|c|c|c|}
\hline \multirow[b]{2}{*}{ Cultivar } & \multicolumn{4}{|c|}{ Annual performance $($ Huia $=100)$} & \multicolumn{4}{|c|}{ Seasonal performance $($ Huia $=100)$} & \multirow{2}{*}{$\begin{array}{c}\begin{array}{c}\text { Stolon } \\
\text { density }\end{array} \\
(1-5)\end{array}$} \\
\hline & Year 1 & Year 2 & Year 3 & Overall & Spring & Summ & Autumn & Winter & \\
\hline Grasslands Huia & 100 & 100 & 100 & 100 & 100 & 100 & 100 & 100 & 2.2 \\
\hline Grasslands Demand & 128 & 135 & 148 & 132 & 144 & 134 & 123 & 135 & 3.4 \\
\hline Grasslands Prestige & 115 & 137 & 146 & 126 & 140 & 127 & 124 & 123 & 3.6 \\
\hline Prop & 92 & 104 & 100 & 98 & 116 & 88 & 97 & 88 & 2.4 \\
\hline Apex & 121 & 127 & 136 & 122 & 128 & 117 & 112 & 155 & 2.6 \\
\hline Grasslands Kopu II & 127 & 106 & 120 & 117 & 122 & 116 & 105 & 128 & 2.0 \\
\hline Grasslands Tribute & 119 & 135 & 171 & 129 & 138 & 129 & 120 & 153 & 2.6 \\
\hline $\operatorname{LSD}_{(0.05)}$ & 10 & 11 & 14 & 13 & 11 & 13 & 11 & 14 & 0.3 \\
\hline
\end{tabular}

Table 5 Annual and stolon density of five white clover cultivars relative to Huia in two trials under rotational sheep grazing in Canterbury.

\begin{tabular}{lcccc}
\hline & \multicolumn{3}{c}{ Annual performance (Huia=100) } & $\begin{array}{c}\text { Stolon } \\
\text { density }\end{array}$ \\
Yultivar & Year 1 & $\begin{array}{c}\text { Year 2 } \\
(\%)\end{array}$ & Overall & $($ no./m²) \\
\hline Grasslands Huia & 100 & 100 & 100 & 1600 \\
Grasslands Kopu & 108 & 64 & 87 & 1075 \\
Grasslands Demand & 149 & 123 & 136 & 2850 \\
NuSiral & 104 & 69 & 81 & 962 \\
Grasslands Tribute & 168 & 137 & 150 & 1825 \\
LSD (0.05) & 12 & 11 & 12 & 564 \\
\hline
\end{tabular}

stolon density than Tribute, while Pitau, Challenge and Kopu had significantly lower stolon density (Table 3). In the South Island trials, Tribute had lower stolon density than the smaller leaved Demand (Tables 4 and 5), but similar stolon density to Apex and Prop (Table 4).

The strong performance of Tribute under summer moisture stress at Lincoln particularly in the third year (Table 5) suggests that further improvements in drought tolerance 
Figure 1 The relationship between Clover root weevil damage and clover productivity under dairy grazing in the Waikato for 20 white clover cultivars. (Adapted from Eerens et al. 2001).

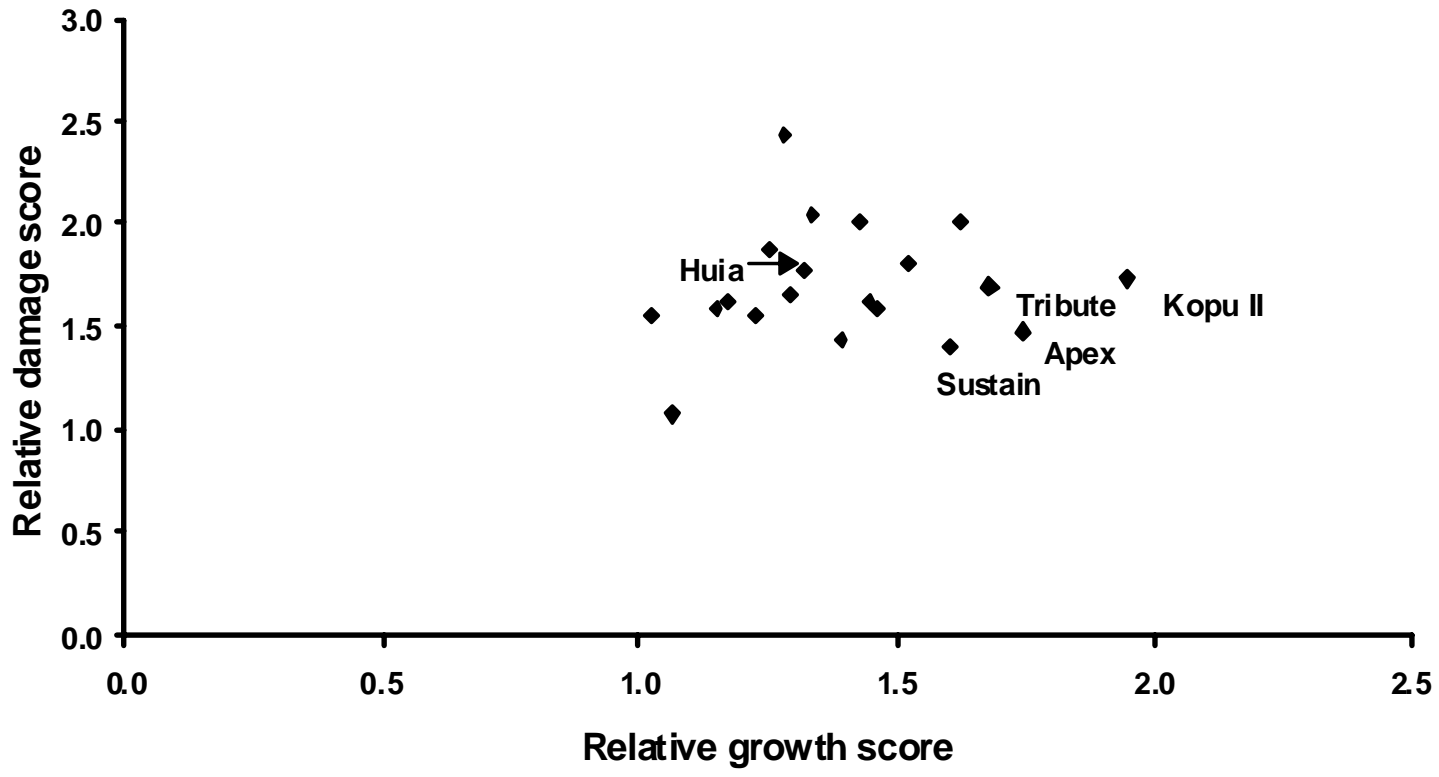

should be possible from continued selection for drought tolerance in Australia.

Tolerance to pests and diseases is an important component in ensuring adequate persistence of new cultivars. Tribute was selected for tolerance to the common foliar diseases that affect white clover performance in New Zealand including viruses, pepper spot and sclerotinia. It has also exhibited a level of tolerance to clover root weevil that is similar to Apex based on trials under dairy grazing in the Waika to (Figure 1).

\section{REFERENCES}

Archer, K.A. ; Robinson, G.G. 1989. The role of stolons and seedlings in the persistence and production of white clover (Trifolium repens L. cv. Huia) in temperate pastures on the northern Tablelands, New South Wales. Australian Journal of Agricultural Research 40: 605-616.

Ayres, J.F.; Caradus, J.R.; Lane, L.A.; Murison, R.D. 1996. White clover breeding for dryland sheep and cattle pastures in Australia. Grassland Research and Practice Series No. 6: 155-158.

Barker, D.J.; Caradus, J.R.; McManus, M.T. 1993. Physiological responses of white clover genotypes to water deficit. Proceedings of the XVII International Grassland Congress: 67-68.

Brock, J.L. 1988. Evaluation of New Zealand bred white clover cultivars under rotational grazing and set stocking with sheep. Proceedings of the New Zealand Grassland Association 49: 203-206.
Caradus, J.R.; Clifford, P.T.P.; Chapman, D.F.; Cousins, G.R.; Williams, W.M.; Miller, J.E. 1997. Breeding and description of 'Grasslands Sustain', a medium-large-leaved white clover (Trifolium repens L.) cultivar. New Zealand Journal of Agricultural Research 40: 1-7.

Caradus, J.R.; Forde, M.B.; Wewala, S.; Mackay, A.C. 1990. Description and classification of a white clover (Trifolium repens L.) germplasm collection from southwest Europe. New Zealand Journal of Agricultural Research 33: 367-375.

Caradus, J.R.; van den Bosch, J.; Woodfield, D.R.; Mackay, A.C. 1991. Performance of white clover cultivars and breeding lines in a mixed species sward. 1. Yield and clover content. New Zealand Journal of Agricultural Research 34: 141-154.

Caradus, J.R.; Williams, W.M. 1989. Breeding for legume persistence in New Zealand. pp. 523-539. In: Persistence of forage legumes. Eds. Martin, G.C. et al. Proceedings of a Trilateral Workshop, Hawaii. American Society of Agronomy, Madison, Wisconsin.

Crush, J.R.; Caradus, J.R. 1995. Cyanogenesis potential and iodine concentration in white clover (Trifolium repens L.) cultivars. New Zealand Journal of Agricultural Research 38: 309-316.

Eerens, J.P.J.; Cooper, B.M.; Willoughby, B.E.; Woodfield, D.R. 2001. Searching for clover root weevil (Sitona lepidus) resistance/tolerance - A progress report. Proceedings of the New Zealand Grassland Association 63: 177-181. 
MAF. 2002. Grant of plant variety rights. New Zealand Plant Variety Rights Journal No. 89: 6. van den Bosch, J.; Black, I.K.; Cousins, G.R.; Woodfield, D.R. 1993. Enhanced drought tolerance in white clover. Proceedings of the New Zealand Grassland Association 55: 97-101.

Williams, W.M.; Sheath, G.W.; Chapman, D.F. 1990. Evaluation of clovers in dry hill country 1. General objectives and description of sites and plant material. New Zealand Journal of
Agricultural Research 33: 521-526.

Woodfield, D.R.; Caradus, J.R. 1987. Adaptation of white clover to moisture stress. Proceedings of the New Zealand Grassland Association 48: 143-149. Woodfield, D.R.; Clifford, P.T.P.; Cousins, G.R.; Ford, J.L.; Baird, I.J.; Miller, J.E.; Woodward, S.L.; Caradus, J.R. 2001. Grasslands Kopu II and Crusader: New generation white clovers. Proceedings of the New Zealand Grassland Association 63: 103-108.

92 - File identification only 